\title{
INTERDISCIPLINARIDADE, CURRÍCULO E TECNOLOGIA: UM ESTUDO SOBRE PRÁTICAS PEDAGÓGICAS NO ENSINO FUNDAMENTAL
}

\author{
INTERDISCIPLINARIEDAD, CURRICULO Y LA TECNOLOGIA: UN ESTUDIO \\ ACERCA DE LAS PRÁCTICAS PEDAGÓGICAS EN EI CONTEXTO DE LA \\ ESCUELA
}

INTERDISCIPLINARY, CURRICULUM AND TECNOLOGY: A STUDY ON THE
PEDAGOGICAL PRACTICE IN THE ELEMENTARY AND MIDDLE SCHOOL

\author{
Mariana Aranha de SOUZA ${ }^{1}$ \\ Ivani Catarina Arantes FAZENDA ${ }^{2}$
}

RESUMO: O presente estudo discute a relação entre Currículo, Interdisciplinaridade e Tecnologia a partir de uma perspectiva epistemológica, metodológica e ontológica. Fundamentado nos estudos de Sacristán (2000) e Moreira e Silva (1999) apresenta-se as principais teorias de currículo e suas implicações no cotidiano da escola. A Interdisciplinaridade, ancorada nos estudos de Fazenda $(2001,2014)$ aponta para as possibilidades de complementaridade entre os saberes e da parceria como essencial à uma prática intencional e contextualizada. Valente (1993) e Silva (2002) defendem que a tecnologia precisa ser integrada ao currículo e que deve contribuir para as discussões que envolvem o cotidiano. A partir de uma perspectiva qualitativa, discutem-se duas práticas pedagógicas realizadas no Laboratório de Informática, com duas turmas de Ensino Fundamental, uma de quinto e outra de oitavo ano, em uma escola de uma rede privada de ensino. As práticas revelaram: i) a importância da parceria entre os professores; ii) a necessidade do trabalho com temáticas advindas de uma perspectiva crítica do currículo; e iii) as possibilidades que o uso da tecnologia oferece às práticas pedagógicas e ao desenvolvimento da autonomia dos alunos, contribuindo para sua formação e para a própria formação dos professores.

PALAVRAS-CHAVE: Currículo. Interdisciplinaridade. Tecnologia. Ensino Fundamental.

RESUMEN: Este estudio analiza la relación entre el Curriculo, la Interdisciplinariedad y la Tecnología desde una abordaje epistemológica, metodológica

1 Doutora em Educação: Currículo e Mestre em Educação: Currículo pela Pontifícia Universidade Católica de São Paulo. Pedagoga pela Faculdade Maria Augusta Ribeiro Daher. Professora do Programa de Pós-Graduação em Educação e Desenvolvimento Humano da Universidade de Taubaté. E-mail: profa.maaranha@gmail.com

${ }^{2}$ Livre Docente em Didática pela UNESP. Doutora em Antropologia pela USP. Mestre em Filosofia pela PUC/SP. Pedagoga pela USP. Professora Titular do Programa de Pos-Graduação em Educação: Currículo da PUC/SP. Coordenadora do GEPI (Grupo de Estudos e Pesquisas em Interdisciplinaridade). Professora Associada do CRIE (Centre de Recherche et Intervention Educative) da Universidade de SherbrookeCanadá. Membro do CIRET/UNESCO. Membro fundador do Instituto Luso Brasileiro de Ciencias da Educação-Universidade de Evora- Portugal. Bolsista de Produtividade em Pesquisa CNPq Nível 1D - CA ED Educação. Email: jfazenda@uol.com.br 
y ontológica. Con base en estudios de Sacristán (2000); Moreira y Silva (1999) presenta las principales teorías curriculares y sus implicaciones en la rutina de la escuela. La interdisciplinariedad, basada en los estudios de Fazenda (2001, 2014) apunta para las posibilidades de complementariedad entre el conocimiento y de la asociación com otros maestros como esencial para la eficacia de una práctica intencional y contextualizada. Valente (1993) y Silva (2007) argumentan que la tecnología necesita ser integrada al curriculo y contribuir a las discusiones que involucran la vida diaria. Desde un punto de vista cualitativo, se discuten dos prácticas pedagógicas con dos clases, un quinto y un octavo año, realizada en el laboratorio de computación en una Red de Escuelas en Brazil. Las prácticas destacan: i) la importancia de la colaboración entre los maestros; ii) la necesidad de trabajar con las cuestiones derivadas de las teorías críticas del currículo; y iii) las posibilidades que el uso de la tecnología ofrecen para las prácticas pedagógicas y el desarrollo de la autonomía de los alumnos, contribuyendo a su formación y el formación de los maestros.

PALAVRAS CLAVE: Curriculo. Interdisciplinariedad. Tecnología. Escuela.

ABSTRACT: In this study is discussed the relationship between curriculum, Interdisciplinarity, and Technology based upon an epistemological, methodological, and ontological perspective. Reasoned on the studies by Sacristán (2000), and Moreira and Silva (1990), this work reports the main theories to the curriculum and their applications on the everyday school. The interdisciplinary, supported by the work by Fazenda (2001,2014), points to the possible complementarity between knowledge and effectiveness of the partnership as essential to an intentional and contextualized practice. Valente (1993) and Silva (2002) stress out that the technology must be integrated into the curriculum and must contribute to the discussion that involves the everyday school. Based upon a qualitative perspective, it is discussed two pedagogical practices carried out in computer labs in two classes of elementary and middle schools of a private school branch, one of the fifth and another of the eighth grades. The practices have shown: $i$ ) the importance of the partnership between teachers; ii) the need to work into thematics coming from critical perspective of the curriculum; and iii) the possibilities to use the technology offers pedagogical practices and development of the autonomy of students, which contribute to their formation and to the own formation of the teachers.

KEYWORDS: Curriculum. Interdisciplinarity. Technology. Elementary and Middle School.

\section{Introdução}

Desde o início do século passado, a instituição escola aparece no Brasil aparentemente com os mesmos moldes que conhecemos hoje: um prédio com salas de aula, carteiras preferencialmente enfileiradas, uma lousa para que o professor possa escrever e todos os alunos acompanharem seus registros, um armário para que o 
professor guarde seus materiais e alguns materiais dos alunos e, por fim, um espaço para que os alunos descansem entre um período e outro. É claro que, ao longo dos anos a forma como se dividem as turmas foi se modificando, ora separadas por gênero, ora por idade, ora por rendimento escolar, por endereço residencial, por ordem alfabética ou interesse do professor. Conforme a ideologia da época, a política, a concepção de escola, de currículo, de ensino e de aprendizagem, a escola assumiu contornos, posturas e realidades diferentes.

É exatamente sobre esta escola que se pretende refletir neste trabalho. Sobre uma escola que se consolidou ao longo da história, que participou de mudanças de ordem cultural, social, política, econômica, curricular e metodológica. Espera-se refletir sobre uma escola que ao longo dos anos vem carregando em si uma tradição escolar e, ao se deparar, já no século XXI com uma era absolutamente tecnológica, em que grande parte de crianças e adolescentes se comunicam via Internet, celular e por meio de outras tecnologias digitais, começa a repensar seu papel e se vê, também, mergulhada nestas tecnologias.

Por este motivo, torna-se fundamental discutir as questões que envolvem currículo, interdisciplinaridade e tecnologia, a partir de duas perspectivas: a teórica, cuja epistemologia e ontologia auxiliam na compreensão dos fenômenos educativos; e a prática, cuja abordagem metodológica possibilita a reflexão sobre como tais relações se sustentam e se efetivam.

\section{Interdisciplinaridade, Currículo e Tecnologia}

A palavra Currículo se origina do latim Curriculum, que significa carreira, curso, percurso, lugar onde se corre, campo, caminho. Deriva, também, do verbo latino currere, que pode ser traduzido como o ato de correr e o percurso feito na pista.

De acordo com Vasconcellos (2009), a partir do século XVI, a palavra curriculum passa a ser aplicada às instituições de ensino, possibilitando a ocorrência de duas grandes vertentes: a de que o currículo não deveria apenas ser seguido e a de que o currículo deveria também ser completado.

Essa afirmação trouxe um sentido maior de controle ao ensino e permite compreender que, quando de discute Currículo, as decisões se encontram no âmbito do 
que deve ser aprendido, como aprender e por que aprendê-lo; ou seja, as escolas devem definir o que deve ser ensinado, como ensinar, para que, para quem e por que ensinar.

Sacritán (2000) aponta que as práticas pedagógicas são orientadas por suas concepções curriculares, as quais traduzem as teorias que as fundamentam. Para o autor, é possível classificar tais teorias em: Teorias Tradicionais, Teorias Críticas e Teorias Pós-críticas de Currículo.

As Teorias tradicionais do Currículo dão ênfase a elementos como: ensino, aprendizagem, avaliação, metodologia, didática, organização, planejamento, eficiência e objetivos; presentes na organização metodológica das escolas e nos cursos de formação de professores ao longo dos anos.

As Teorias Críticas de Currículo, por sua vez, privilegiam elementos como: ideologia, reprodução cultural e social, poder, classe social, capitalismo, relações sociais de produção, conscientização, emancipação e libertação, currículo oculto e resistência. E as Teorias Pós-críticas de Currículo dão ênfase a identidade, alteridade, diferença, subjetividade, significação e discurso, saber-poder, representação, cultura, gênero, raça, etnia, sexualidade e multiculturalismo.

Para se consolidarem, tais teorias necessitaram de um consenso. "Nesse sentido, currículo tem a ver diretamente com a questão do poder, o que vai, inclusive, separar as teorias tradicionais das teorias críticas e pós-críticas do currículo" (PADILHA, 2004, p. 123).

Nesse sentido, Sacristán (2000) aponta que as teorias tradicionais aparentemente se apresentam como neutras, científicas e desinteressadas, já que defendem que os saberes dominantes definem o que ensinar e as técnicas aplicadas servem para que o ensino aconteça na escola, mas, no entanto, revelam uma forma de ver e pensar o mundo, ou seja, sua ideologia.

As teorias críticas e pós-críticas não aceitam, de forma alguma, esta maneira de pensar o Currículo. Para os que defendem esta concepção, sempre deve existir um questionamento sobre o porquê trabalhar determinados conhecimentos em detrimento de outros, tentando entender a ideologia oculta sob um aparente rótulo de neutralidade científica, uma vez que o currículo

[...] tem significados que vão muito além daqueles aos quais as teorias tradicionais nos confinaram. O currículo é lugar, espaço, território. O currículo é relação de poder. O currículo é trajetória, viagem, 
percurso. O currículo é autobiografia, nossa vida, curriculum vitae: no currículo se forja nossa identidade. O currículo é texto, discurso, documento. O currículo é documento de identidade (MOREIRA e SILVA, 1995, p. 150).

Para Sacristán (2000), a escola é constituída por um projeto educativo complexo que reflete a função socializadora da educação, que está muito além do que ingenuamente costuma se pensar sobre currículo, como sendo apenas o conjunto de disciplinas pré-definidas que compõem um plano de ensino. Na verdade, a forma como estas disciplinas se organiza, se relaciona e como se pensa estas disciplinas é o que definirá quais concepções curriculares orientam determinada escola.

Acredita-se no diálogo como uma possibilidade real para a efetivação de tais práticas. Quando a escola cria ambientes nos quais o diálogo é possível, o movimento a que as teorias críticas e pós-críticas se referem passam a se constituir efetivamente nas práticas das escolas de forma intencional e planejada.

Sob esta perspectiva, a interdisciplinaridade proposta por Fazenda (2014) apresenta possibilidades de convergência entre as disciplinas a partir de seus pontos de intersecção. Tais pontos se apresentam tanto na estrutura conceitual e metodológica das disciplinas, como propõem as teorias tradicionais de currículo, quanto em sua estrutura relacional e socializadora, na qual estão inseridos os temas que permeiam o cotidiano dos alunos e o mundo no qual estão inseridos, como propõem as teorias críticas e póscríticas de currículo.

Por este motivo, Fazenda (2001, p. 11) afirma que a interdisciplinaridade "é uma nova atitude diante da questão do conhecimento, de abertura à compreensão de aspectos ocultos do ato de aprender e dos aparentemente expressos colocando-os em questão". A partir da perspectiva da interdisciplinaridade, reconhece-se que o conhecimento não é algo fragmentado, mas que se conecta com outros conhecimentos, estabelecendo relações de proximidade e possibilitando que os sujeitos, com os quais o conhecimento interage, possam questionar as certezas até então encontradas.

A interdisciplinaridade propõe que todo conteúdo ou tema trabalhado na escola considere aspectos epistemológicos (de ordem conceitual), metodológicos (de ordem prática) e ontológicos (de ordem existencial), necessários à compreensão do todo que envolve o próprio conhecimento e que, consequentemente, interfere na formação do aluno (FAZENDA, 2008). Segundo a autora, "exige, portanto, na prática uma profunda imersão no trabalho cotidiano" (FAZENDA, 2001, p. 11). 
É sob esta perspectiva que se compreende a inserção das tecnologias nos currículos e, consequentemente, nas práticas pedagógicas das escolas. Acredita-se que as tecnologias compõem novas possibilidades de interação dos alunos com o conhecimento, com as próprias tecnologias, com os professores e com os demais colegas, em um movimento que acompanha o próprio movimento curricular que a escola está inserida. Isso significa afirmar que, em uma escola, cuja proposta curricular considera a necessidade do diálogo, do trabalho colaborativo, da efetivação de práticas interdisciplinares, da construção da identidade e do respeito às diferenças, o uso das tecnologias inevitavelmente caminhará também por esta seara, como aponta Silva (2002):

Pensamos que a ideia de escola como memória da humanidade, como sistema de construção do saber, de enriquecimento moral e social, um espaço em que se considere cada aluno como um ser humano à procura de si próprio, em reflexão conjunta com os demais e com o mundo que o rodeia, tem ainda razão de existir neste início de um novo milênio. Precisa, sim, é de ser profundamente renovada e as actuais TIC contém os ingredientes necessário para favorecer essa mudança (SILVA, 2002, p. 34).

Acredita-se que o uso das tecnologias na escola seja incorporado às concepções e práticas curriculares por ela adotadas. Na medida em que a escola assume sua natureza ideológica, seu posicionamento acerca de como compreende seu papel social e como o coloca em prática no seu cotidiano, todos os que nela trabalham assumem seu papel de forma coerente e intencional. Isso pode ser observado nas práticas pedagógicas, na formação de professores, no uso das tecnologias e nas relações que os alunos estabelecem entre si, com os professores e com o próprio conhecimento.

\section{Metodologia e Contexto da Pesquisa}

Acredita-se, como Minayo (2004), que a abordagem qualitativa da pesquisa permite que se trabalhe com o universo de significados, motivos, aspirações, crenças, valores e atitudes presentes nos processos, nos fenômenos e nas relações, os quais não podem ser reduzidos à operacionalização de varáveis.

Martins (1994, p. 51), por sua vez, afirma que "os conceitos sobre os quais as Ciências Humanas se fundamentam, num plano de pesquisa qualitativa, são produzidos pelas descrições". Este artigo pretende descrever e analisar duas práticas realizadas com 
alunos do Ensino Fundamental (quinto e oitavo ano) que ocorreram no Laboratório de Informática de uma escola, pertencente a uma rede privada de ensino.

A escola, cujas práticas serão descritas e analisadas, está situada na cidade de São Paulo, atende toda a Educação Básica (Educação Infantil, Ensinos Fundamental e Médio) e Educação de Jovens e Adultos. O Laboratório de Informática desta escola dispõe de um professor de Informática responsável, que ministra aulas semanalmente para os alunos dos anos finais do Ensino Fundamental e também trabalha com agendamentos para os professores dos anos iniciais do Ensino Fundamental, Educação Infantil, Ensino Médio e Educação de Jovens e Adultos.

\section{Livro da Vida: uma experiência no quinto ano do Ensino Fundamental}

Os Anos Iniciais do Ensino Fundamental na Rede Escolar estudada têm seu currículo organizado por Eixos de Trabalho, nos quais temas se articulam de forma a permitir que os alunos possam criar uma rede de conexões lógicas sobre o que é proposto pelos professores. Um dos temas propostos para o quinto ano é a elaboração do "Livro da Vida", no qual os alunos devem registrar aspectos importantes de sua história até o momento presente.

Fazenda (2003) afirma que é de extrema importância que professores e alunos compreendam suas Histórias de Vida, uma vez que elas fazem parte de uma história maior: a história do mundo que as rodeia. Este conceito compõe o que Sacristán (2000) aponta como necessário para a efetivação de uma teoria pós-crítica de currículo, na qual aspectos que compreendem a vida de alunos e professores são discutidos no cotidiano da escola.

A professora do quinto ano planejou a sequência de atividades para a elaboração do Livro da Vida em parceria com a professora de Informática. A ferramenta básica utilizada seria um editor de texto (Word for Windows), pois o livro seria escrito utilizando o gênero textual "diário" e os alunos realizariam as atividades no Laboratório de Informática uma vez por semana.

As professoras estabeleceram um cronograma de trabalho, considerando os seguintes procedimentos: diagnosticar os conhecimentos prévios dos alunos sobre o 
conteúdo a ser trabalhado, sobre o gênero textual utilizado e sobre o editor de texto que seria utilizado, bem como os recursos necessários para sua formatação.

De acordo com as professoras, a grande maioria dos alunos apresentava erros ortográficos que tornavam a correção individual pelo professor e a reescrita do aluno muito lenta e trabalhosa. Optou-se, então, por orientar os alunos a digitarem seus textos no Word e observarem o que o corretor de texto apontava como erro, a fim de que cada aluno tivesse autonomia para verificarem quais erros cometeu e procurar a escrita correta. Dessa forma, o aluno não precisaria mais reescrever o texto inteiro em caso de algum erro, mas apenas corrigir a palavra escrita de forma equivocada.

Os alunos também foram orientados a utilizarem sites de busca na Internet para pesquisarem de forma autônoma. Fizeram isso em uma das aulas para descobrir a origem do próprio nome.

De igual forma, utilizaram informações colhidas com os próprios pais em casa, advindas de entrevistas e da seleção de fotos e desenhos para organizarem e diagramarem cada um o seu Livro. Uma aluna escreveu o seguinte depoimento:

Fazer meu próprio livro foi muito interessante porque é legal falar um pouco sobre a sua vida, e este livro também ensinou varias coisas como: algumas pessoas não sabiam mexer no computador e a professora ensinou quem não sabia mexer no computador e aprendemos muitas coisas com este livro de nossas vidas (Aluna 1).

Após ser revisto por alunos e professores, o Livro foi impresso no próprio Laboratório de Informática e entregue às famílias na Reunião de Pais.

Fazenda (2001, p. 12) afirma que "todo projeto interdisciplinar nasce de um lócus bem delimitado; portanto, é preciso contextualizar para poder conhecer". Para que o trabalho com o Livro da Vida se efetivasse foi necessário conhecer as características que compõem um livro dessa natureza, sob a perspectiva histórica e sob a perspectiva metodológica, do gênero textual escolhido. No entanto, outros recursos também precisaram ser conhecidos e discutidos, como a questão das identidades dos alunos, dos tempos, e do próprio uso da tecnologia. E tal reflexão se fez em uma "ação em movimento", da qual fala Fazenda (2001), numa dinâmica em que não é possível separar os conhecimentos em compartimentos, mas que permite que eles dialoguem e se concretizem em uma prática, de fato mais crítica, como propõe Sacristán (2000) e Silva (2002). 


\section{Anúncio publicitário: uma experiência com o oitavo ano do Ensino Fundamental}

Os Anos Finais do Ensino Fundamental da escola estudada têm seu currículo organizado por disciplinas, e a informática educacional é uma delas. A proposta de trabalho nesta disciplina é articular o ensino das tecnologias ao conteúdo das demais disciplinas de cada ano/série. Pretende-se aqui descrever e analisar uma experiência realizada em parceria com a disciplina de Língua Portuguesa no oitavo ano do Ensino Fundamental.

Como Fazenda (2003, p. 69), acredita-se que "a parceria consiste numa tentativa de incitar o diálogo com outras formas de conhecimento que não estamos habituados e, nessa tentativa, a possibilidade de que um pensar venha se complementar no outro".

As professoras de Língua Portuguesa e de Informática organizaram seu trabalho da seguinte forma: inicialmente, a professora de Língua Portuguesa trabalhou com os alunos o gênero "anúncio publicitário", explorando o conceito, suas características e formas de aplicação. Em seguida, a professora de Informática propôs que os alunos se organizassem em duplas e criassem um produto fictício (utilizando material reciclável), que precisaria ser supostamente vendido e, portanto, precisaria também ser anunciado. $\mathrm{O}$ anúncio do produto deveria ser feito de duas formas: um cartaz (utilizando o Word e o Paint) e um vídeo (utilizando o Movie Maker).

As atividades de construção do produto com material reciclável e de elaboração do cartaz deveriam ser realizadas nas aulas de Informática, nas quais as duplas de alunos trabalhariam colaborativamente. Uma dupla poderia interagir com a outra e com a professora. $\mathrm{O}$ vídeo, por sua vez, poderia ser gravado em qualquer ambiente (escola, casa, rua) e editado no Laboratório de Informática da escola. Para esta etapa a professora de Informática apresentou os recursos de edição de vídeo e as duplas de alunos passaram novamente a interagir entre si e com a professora.

Uma das duplas de alunos criou um produto denominado "Digitexto", como demonstra a Figura 1: 
Figura 1: Anúncio publicitário: Digitexto

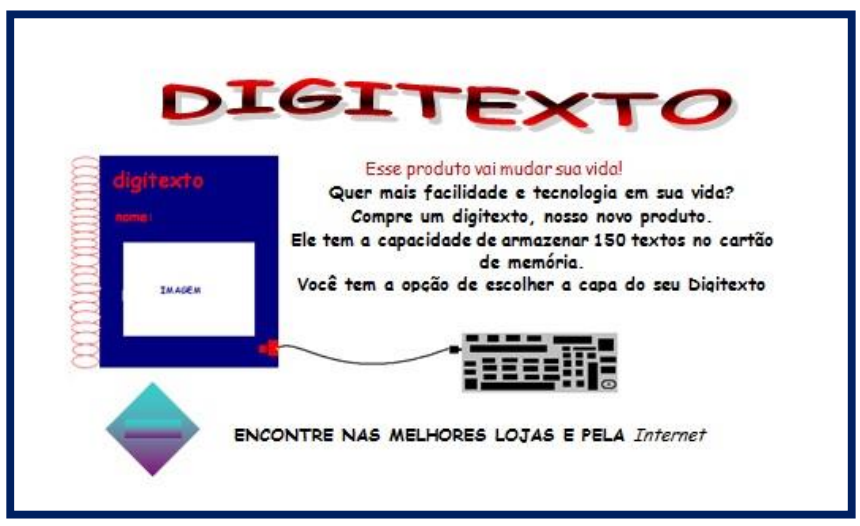

Fonte: Registros de pesquisa das autoras: Dupla 1.

A dupla que produziu o "Digitexto" afirmou que havia pensado em um produto que respeitasse as exigências da escola (em que os alunos deveriam ter cadernos e livros), mas que, ao mesmo tempo, acompanhasse as inovações tecnológicas presentes na vida dos adolescentes: para eles, digitar era uma ação muito mais rápida e eficaz do que escrever com papel e caneta. Além disso, segundo eles, o produto armazenaria mais de cento e cinquenta textos em um único cartão de memória, diminuindo o peso das mochilas e facilitando a localização dos textos solicitados pelo professor, já que poderiam armazenar todos eles em pastas, separadas por disciplina e por temas, sem ocupar tanto espaço. Para elaborar de forma fictícia o produto, os alunos utilizaram materiais recicláveis, como caixas de papelão e retalhos de isopor.

Já uma segunda dupla criou um produto chamado "Tradutone", como demonstra a Figura 2: 
Figura 2: Anúncio publicitário: Tradutone

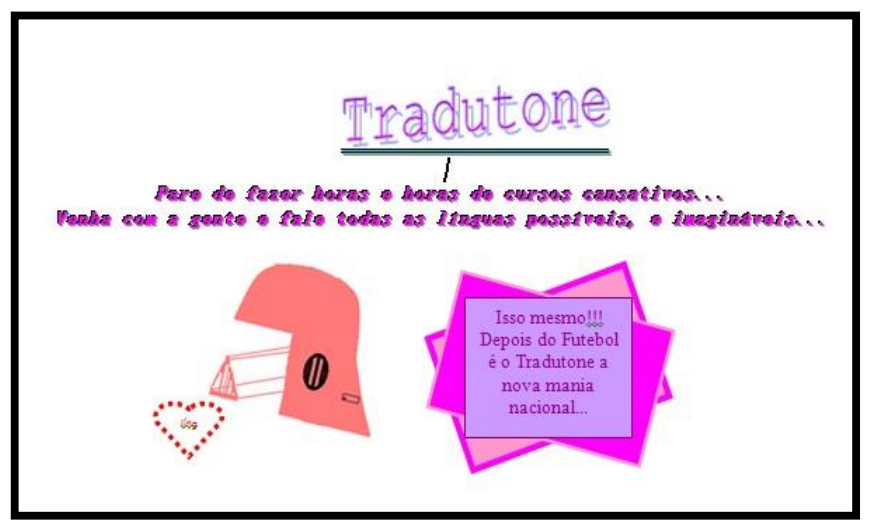

Fonte: Registros de pesquisa das autoras: Dupla 2.

Para a segunda dupla, um produto interessante deveria ser composto por um capacete que mudaria a relação dos adolescentes com os diversos idiomas. Para eles bastaria colocar o capacete - o qual denominaram de "Tradutone" - que sua tecnologia já identificaria qual o idioma falado e o traduziria imediatamente para a língua materna do usuário. Como a primeira dupla, esta também utilizou material reciclado para elaborar o produto e apresentá-lo aos demais colegas.

Após a criação do cartaz, cada dupla filmou o anúncio de seu produto, utilizando-se de uma câmera digital e do aplicativo Movie Maker. Todo o processo (filmagem, editoração, diagramação e finalização) foi responsabilidade dos componentes da dupla em parceria com a professora de Informática. Como atividade final, as duplas apresentaram seus produtos, cartazes e vídeos para toda a turma e para as professoras de Língua Portuguesa e Informática, as quais puderam avaliar tanto o processo de construção dos produtos quanto o produto final e sua apresentação.

Esta experiência remete à afirmação de Valente (1993), a qual aponta que

Os computadores estão propiciando uma verdadeira revolução no processo de ensino aprendizagem. Uma razão mais óbvia advém dos diferentes tipos de abordagens de ensino que podem ser realizados através do computador, devido aos inúmeros programas desenvolvidos para auxiliar o processo de ensino-aprendizagem. Entretanto, a maior contribuição do computador como meio educacional advém do fato do seu uso ter provocado o questionamento dos métodos e processos de ensino utilizados (VALENTE, 1993, p.25). 
Acredita-se que a incorporação da tecnologia à aula compõe uma prática atrelada ao currículo da escola, às suas formas de organização e sistematização. Ao assumir um posicionamento de que o conhecimento está em constante transformação, como estão em transformação os alunos, os professores, a escola e a própria sociedade, a inserção da tecnologia às práticas pedagógicas também ocorre de forma intencional e coerente com tais transformações, como pode ser observado nas práticas descritas.

\section{Considerações Finais}

A discussão sobre Interdisciplinaridade, Currículo e Tecnologia aponta para uma temática atual que envolve considerar aspectos de ordem epistemológica, metodológica e ontológica, como sugere Fazenda (2014).

A reflexão epistemológica dos três temas exige clareza sobre as concepções que fundamentam as teorias de currículo, como elas se articulam e em que momento se aproximam ou se distanciam umas das outras. Também evidencia os fundamentos da Interdisciplinaridade e as possibilidades que ela oferece de se pensar sobre como o conhecimento é construído e como ele se articula com outros conhecimentos, com a realidade social e com os sujeitos a sua volta.

Sob essa perspectiva, sugere-se que a inserção da tecnologia ocorra de forma coerente com a concepção curricular que a escola possui. Na medida em que se permite um diálogo intencional acerca de como o conhecimento e as transformações sociais, culturais e tecnológicas ocorrem, as práticas pedagógicas passam a incorporar estas transformações, o que privilegia uma reflexão de ordem metodológica.

A descrição das duas práticas envolvendo atividades realizadas em um Laboratório de Informática com alunos dos anos iniciais e finais do Ensino Fundamental apontam possibilidades em como promover que temas advindos das teorias críticas e pós-críticas de currículo ganhem espaço nas atividades desenvolvidas em sala de aula, articulando-se de forma intencional e planejada com as tecnologias já presentes no cotidiano de alunos e professores.

Fazenda (2001) aponta que a parceria é uma possibilidade concreta de se pensar sobre a Interdisciplinaridade e de exercê-la na prática. Para a autora, esta parceria se realiza entre os professores, entre professores e alunos, entre os próprios alunos e entre professores, alunos e os autores estudados. Ao se estabelecer práticas dessa natureza, 
assume-se uma postura comprometida com o conhecimento, com o currículo e com a realidade social e tecnológica que se transforma a todo momento. Nesse sentido, acredita-se que os temas advindos das teorias pós-críticas de currículo possibilitam que a realidade vivida seja observada e refletida a partir de uma perspectiva ontológica, preocupada com as temáticas de identidade e alteridade.

Espera-se que, evidenciando práticas que consideram a Tecnologia integrada a $\Theta$ um Currículo mais crítico e a Interdisciplinaridade como possibilidade de complementaridade entre saberes e de parceria entre os sujeitos, novas práticas possam ser pensadas e desenvolvidas.

\section{Referências}

FAZENDA, I. C. A. (Org.) Dicionário em construção: Interdisciplinaridade. São Paulo: Cortez, 2001.

FAZENDA, I. C. A. Interdisciplinaridade: qual o sentido? São Paulo: Paulus, 2003.

FAZENDA, I. C. A (Org.). O que é Interdisciplinaridade? São Paulo: Cortez, 2008.

FAZENDA, I. C. A (Org.). Interdisciplinaridade: pensar, pesquisar e intervir. São Paulo:Cortez, 2014.

MARTINS, J. A pesquisa qualitativa. In: FAZENDA, I.C.A. Metodologia da pesquisa educacional. São Paulo: Cortez, 1994.

MINAYO, M.C.S. Pesquisa social: teoria, método e criatividade. Petrópolis: Vozes, 2004.

MOREIRA, A. F.; SILVA, T. T. (Org.). Currículo, cultura e sociedade. 2 ed. São Paulo: Cortez, 1999.

PADILHA, P. R. Currículo intertranscultural: novos itinerários para a educação. São Paulo: Cortez e Instituto Paulo Freire, 2004.

SACRISTAN, J. G. O Currículo: uma reflexão sobre a prática. Porto Alegre: Artes Médicas, 2000.

SILVA, B. D. S. A tecnologia é uma estratégia para a renovação da escola. Movimento. Revista de Educação. Universidade Federal Fluminense. n.05, p. 28-44, 2002.

Disponível em: <http://hdl.handle.net/1822/17223>. Acesso em: 25 out. 2011.

VALENTE, J. A. Diferentes usos do Computador na Educação. Em aberto. Brasília, ano 12, n. 57, p. 3-16, 1993. Disponível em:

<http://emaberto.inep.gov.br/index.php/emaberto/article/view/1876/1847> Acesso em: 11 nov. 2011. 
VASCONCELLOS, C. S. Currículo: a atividade humana como princípio educativo. São Paulo: Libertad, 2009.

\section{Como referenciar este artigo}

SOUZA, Mariana Aranha de.; FAZENDA, Ivani Catarina Arantes. Interdisciplinaridade, Currículo e Tecnologia: um estudo sobre práticas pedagógicas no Ensino Fundamental. Revista Ibero-Americana de Estudos em Educação, Araraquara, v. 12, n. 2, p. 708-721, 2017. Disponível em: <http://dx.doi.org/10.21723/riaee.v12.n2.8303>. E-ISSN: 1982-5587.

Recebido em: 19/01/2016

Aprovação final em: 30/03/2017 